\title{
IDENTIFIKASI FAKTOR-FAKTOR PEMICU KEKERASAN DALAM RUMAH TANGGA DI KOTA DENPASAR
}

\author{
Laily A.A. Arifianti $^{1 \mathrm{a} \S}$, K. Jayanegara ${ }^{1 \mathrm{~b}}$, G.K. Gandhiadi $^{1 \mathrm{c}}$, Eka N. Kencana $^{1 \mathrm{~d} \S}$ \\ ${ }^{1}$ Program Studi Matematika - Universitas Udayana \\ Kampus Bukit Jimbaran, Badung 80361 \\ a lailyardhia@gmail.com, ${ }^{\mathrm{b}}$ ketut_jayanegara@yahoo.com, \\ c gandhiadigk@yahoo.com, i.putu.enk@unud.ac.id \\ ${ }^{\S}$ Corresponding Author
}

\begin{abstract}
Family or domestic violence is meant as a pattern of someone behavior that abuse his/or her power against another member(s) in a family or domestic setting. Knowing the underlying factors that trigger family violence are important to keep family members form a harmonious relationship. This work is aimed to elaborate those factors. By analyzing primary data from 120 respondents whom witness and well informed about family violence in their neighborhoods, factor analyzes is applied. Data are collected by using tested questionnaires. The results showed they were six underlying factors for family violence with total accounted for all factors were 65.19 percent. Those factors are (a) social relationship, (b) job description, (c) past experience, (d) supporting factor, (e) economics' status, and $(f)$ harmonious relationship level. From these factors, social relationship dominates the others with variance explained for family violence as much as 21.39 percent.
\end{abstract}

Keywords: family violence, factor analysis, social relationship.

\section{PENDAHULUAN}

Merujuk kepada Undang-undang Nomor 23 Tahun 2004 tentang Penghapusan Keke-rasan dalam Rumah Tangga (KDRT), KDRT merupakan perbuatan seseorang terhadap orang lain yang mengakibatkan penderitaan secara fisik, seksual, psikologis dan/atau penelantaran rumah tangga, termasuk pula pemaksaan dan perampasan kemerdekaan serta ancaman untuk melakukan perbuatan yang melawan hukum dalam ruang lingkup rumah tangga. Kasus KDRT yang tercatat terjadi di Kota Denpasar cendrung menurun pada periode tahun 20122015, menurut data dari POLRESTA Kota Denpasar, namun jumlah KDRT yang terjadi pada tahun 2015 tercatat ada 66 kasus, rata-rata 5.5 kasus per bulan seperti terlihat pada Gambar 1.

Studi yang dilakukan oleh Prantiasih et al. (2015) tentang perlindungan hak perem-puan sebagai korban KDRT menyimpulkan lelaki melakukan tindak KDRT disebabkan karena tidak memiliki pekerjaan yang tetap serta memiliki karakter temperamental. Tindak KDRT seringkali bisa menyebabkan trauma jangka panjang kepada anak-anak pasangan pelaku dan korban. Manumpahi et al. (2016) menyimpulkan KDRT dapat menyebabkan pertumbuhan dan perkem-bangan jiwa anak terganggu, dan menye-butkan faktor internal dan faktor eksternal keluarga merupakan pemicu terjadinya tindak KDRT.

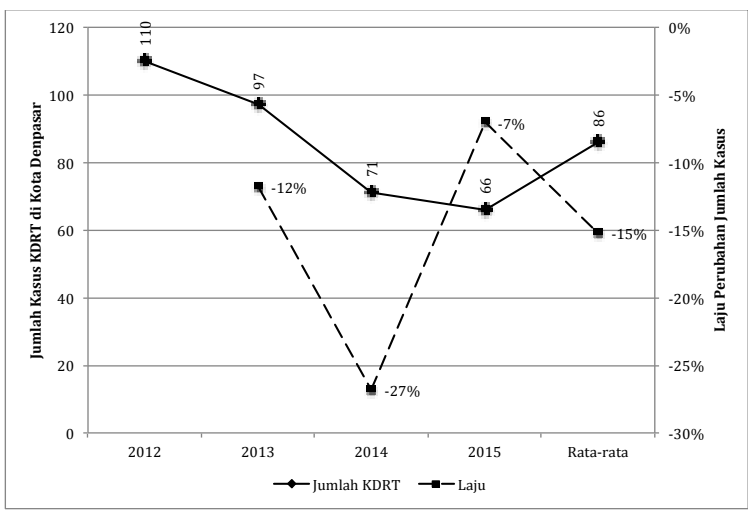

Gambar 1. Kasus KDRT di Kota Denpasar Periode Tahun 2012 - 2015 
Terdapat 5 faktor asumsi pemicu KDRT dalam penelitian ini yaitu faktor kepribadian pelaku, pendapatan pelaku, kebersamaan keluarga pelaku, karakteristik pekerjaan pelaku dan lingkungan tempat tinggal.

Memperhatikan dampak yang ditimbulkan terjadinya tindak KDRT tidak hanya pada pelaku dan/atau korban, juga berpeluang berdampak terhadap anak-anak dari pasangan tersebut, maka perlu diketahui faktor-faktor yang memicu tindak KDRT, khususnya di Kota Denpasar. Penelitian ini ditujukan untuk (a) mengetahui faktor-faktor pemicu tindak KDRT di Kota Denpasar, dan (b) mengidentifikasi faktor pemicu dominan dari tindak KDRT.

\section{METODE PENELITIAN}

\section{A. Metode Pengumpulan Data}

Data penelitian ini diperoleh dengan menyebarkan kuesioner kepada 120 orang penduduk Kota Denpasar yang dipilih secara purposive sejalan dengan tujuan penelitian. Pertimbangan-pertimbangan yang digunakan dalam memilih responden adalah:

1. Responden merupakan tetangga dari pelaku dan/atau korban tindak KDRT;

2. Responden berusia setidak-tidaknya 20 tahun dan tidak memiliki hubungan kekerabatan dengan pelaku dan/ atau korban, agar tidak terjadi bias;

3. Responden mengetahui dengan jelas tindak KDRT yang terjadi.

Menggunakan notasi matriks, persamaan (1) bisa dinyatakan dalam bentuk

$$
\begin{aligned}
& \left(\begin{array}{c}
x_{1} \\
\vdots \\
x_{p}
\end{array}\right)=\left(\begin{array}{ccc}
\gamma_{11} & \ldots & \gamma_{1 m} \\
\vdots & \ddots & \vdots \\
\gamma_{p 1} & \ldots & \gamma_{p m}
\end{array}\right)\left(\begin{array}{c}
\mathrm{F}_{1} \\
\vdots \\
\mathrm{F}_{m}
\end{array}\right)+\left(\begin{array}{c}
\varepsilon_{1} \\
\vdots \\
\varepsilon_{p}
\end{array}\right) \\
& \text { atau } \quad \mathrm{X}_{p x 1}=\Lambda_{p x m} \mathrm{~F}_{m x 1}+\varepsilon_{p x 1}
\end{aligned}
$$

Responden yang terpilih diminta mengisi kuesioner dengan item-item penyusunnya berupa pernyataan tertutup dengan lima opsi jawaban. Sebelum didistribusikan, kuesioner diperiksa validitas dan reliabilitasnya menggunakan pilot test kepada 30 orang yang bukan anggota dari responden terpilih.

Pengujian validitas dan reliabilitas dari kuesioner dilakukan pada Agustus 2016, dan pengumpulan data primer menggunakan kuesioner yang telah direvisi dilakukan pada September - Oktober 2016.

\section{B. Metode Analisis Data}

Pendekatan kuantitatif digunakan untuk menganalisis data yang terkumpul sehingga faktor-faktor pemicu tindak KDRT dapat diidentifikasi. Metode analisis faktor (AF) bertipe Explanatory Factor Analysis (CFA) dipilih untuk mereduksi variabel yang diwakili oleh item-item penyusun kuesioner dan teknik analisis komponen utama (AKU) digunakan untuk membentuk faktor.

Bila terdapat $p$ variabel yang akan direduksi menjadi $m$ faktor dengan $m \leq p$, maka bisa dibentuk model AKU berikut:

$$
\begin{gathered}
\mathrm{X}_{1}=\gamma_{11} \mathrm{~F}_{1}+\gamma_{12} \mathrm{~F}_{2}+\cdots+\gamma_{1 m} \mathrm{~F}_{m}+\varepsilon_{1} \\
\mathrm{X}_{2}=\gamma_{21} \mathrm{~F}_{1}+\gamma_{22} \mathrm{~F}_{2}+\cdots+\gamma_{2 m} \mathrm{~F}_{m}+\varepsilon_{2} \\
\vdots \\
\mathrm{X}_{p}=\gamma_{p 1} \mathrm{~F}_{1}+\gamma_{p 2} \mathrm{~F}_{2}+\cdots+\gamma_{p m} \mathrm{~F}_{m}+\varepsilon_{p}
\end{gathered}
$$

\section{HASIL PENELITIAN}

\section{A. Uji Validitas dan Reliabilitas}

Merujuk pendapat Churchill (1979), sebuah item penyusun dianggap valid digunakan sebagai refleksi suatu konsep bila nilai korelasinya dengan total item yang lain $\geq 0.30$ dan konsep yang diukur bisa dipercaya bila nilai alpha $(\alpha)$ Cronbach $\geq 0.60$ [4]. Mengacu pada kedua pendapat ini, validitas item dan reliabilitas kuesioner diuji dengan perangkat lunak SPSS 23. Hasil uji diperlihatkan pada Tabel 1. 
Tabel 1. Uji Validitas Item dan Reliabilitas

\begin{tabular}{|c|c|c|}
\hline Item Pernyataan & Korelasi & Nilai $\alpha$ \\
\hline \multicolumn{3}{|c|}{ Konsep Kepribadian Pelaku KDRT; $\alpha=0.695$} \\
\hline $\mathrm{X}_{11} \begin{array}{l}\text { Sering mengonsumsi } \\
\text { minuman beralkohol }\end{array}$ & 0.602 & 0.609 \\
\hline $\mathrm{X}_{12}$ Pencemburu dan posesif & 0.523 & 0.628 \\
\hline $\mathrm{X}_{13}$ Cenderung paranoid & 0.503 & 0.634 \\
\hline $\begin{array}{l}\mathrm{X}_{14} \begin{array}{l}\text { Cenderung 'mau menang } \\
\text { sendiri' }\end{array}\end{array}$ & 0.414 & 0.659 \\
\hline $\begin{array}{l}\mathrm{X}_{15} \text { Memiliki pengalaman buruk } \\
\text { di masa lalu }\end{array}$ & 0.373 & 0.670 \\
\hline $\mathrm{X}_{16}$ Sangat mudah marah & 0.519 & 0.632 \\
\hline $\mathrm{X}_{17}$ Selingkuh & $\underline{0.009}$ & $\underline{0.768}$ \\
\hline \multicolumn{3}{|c|}{ Konsep Pendapatan Pelaku KDRT; $\alpha=0.660$} \\
\hline $\mathrm{X}_{21}$ Pendapatan tidak menentu & 0.492 & - \\
\hline $\begin{array}{ll}\mathrm{X}_{22} & \text { Ketergantungan yang tinggi } \\
\text { secara finansial korban pada } \\
\text { pelaku }\end{array}$ & 0.492 & - \\
\hline \multicolumn{3}{|c|}{ Konsep Kebersamaan Keluarga Pelaku; $\alpha=0.615$} \\
\hline $\begin{array}{ll}\mathrm{X}_{31} & \text { Pelaku jarang memiliki waktu } \\
& \text { bersama keluarga }\end{array}$ & 0.540 & 0.535 \\
\hline $\mathrm{X}_{32}$ Jarang bersama korban & $\underline{0.269}$ & $\underline{0.610}$ \\
\hline $\mathrm{X}_{33}$ Ada anggota keluarga sakit & 0.342 & 0.576 \\
\hline $\begin{array}{ll}\mathrm{X}_{34} & \begin{array}{l}\text { Korban cenderung lalai dalam } \\
\text { mengurus keluarga }\end{array} \\
\end{array}$ & 0.424 & 0.531 \\
\hline $\begin{array}{ll}\mathrm{X}_{35} & \begin{array}{l}\text { Komunikasi antara pelaku } \\
\text { dengan korban jarang }\end{array} \\
\end{array}$ & 0.396 & 0.550 \\
\hline \multicolumn{3}{|c|}{ Konsep Karakteristik Pekerjaan Pelaku; $\alpha=0.805$} \\
\hline $\mathrm{X}_{41}$ Tingkat kesulitan tinggi & 0.646 & 0.739 \\
\hline $\mathrm{X}_{42}$ Tingkat resiko tinggi & 0.854 & 0.495 \\
\hline $\mathrm{X}_{43}$ Relasi kerja buruk & 0.488 & 0.889 \\
\hline \multicolumn{3}{|c|}{ Konsep Lingkungan Tempat Tinggal; $\alpha=0.600$} \\
\hline $\begin{array}{ll}\mathrm{X}_{51} & \begin{array}{l}\text { Hubungan kurang baik } \\
\text { dengan tetangga }\end{array} \\
\end{array}$ & 0.435 & 0.488 \\
\hline $\mathrm{X}_{52}$ Ada kesenjangan ekonomi & 0.409 & 0.507 \\
\hline $\mathrm{X}_{53}$ Kesenjangan gender & 0.358 & 0.547 \\
\hline $\mathrm{X}_{54}$ Penegakan hukum lemah & 0.329 & 0.574 \\
\hline
\end{tabular}

Tabel 1 menunjukkan lima konsep yang diasumsikan sebagai penyebab terjadinya tindak KDRT. Konsep-konsep ini mengacu kepada hasil penelitian sebelumnya. Pada konsep kepribadian pelaku KDRT, dari tujuh item pengukur konsep ini, item $\mathrm{X}_{17}$ memiliki nilai korelasi dengan total item lain pada konsep yang sama hanya sebesar 0.009 ; jauh lebih kecil dari nilai ambang 0.30 yang dipersyaratkan. Bila $\mathrm{X}_{17}$ dieliminasi, koefisien $\alpha$ meningkat dari 0.695 menjadi 0.768 yang berarti $\geq 0.60$. Memperhatikan hal ini, diputuskan untuk mengeliminasi $\mathrm{X}_{17}$ dari analisis berikutnya.

Konsep kedua - pendapatan pelaku - yang disusun oleh 2 item, memiliki nilai koefisien korelasi $\geq 0.30$ dan nilai koefisien $\alpha \geq 0.60$. Disimpulkan, $\mathrm{X}_{21}$ dan $\mathrm{X}_{22}$ merupakan item-item yang valid dalam mengukur pendapatan rumah tangga pelaku dan/atau korban KDRT.

Pada konsep kebersamaan, dari lima item penyusun, diperoleh $\mathrm{X}_{32}$ (alokasi waktu yang digunakan pelaku bersama anggota keluarga) memiliki nilai korelasi sebesar 0.269. Meski nilai ini lebih kecil dari 0.30, mempertimbangkan bila item $\mathrm{X}_{32}$ dieliminasi hanya menambah nilai koefisien $\alpha$ sebesar 0.05 , maka diputuskan untuk mempertahankannya pada analisis berikutnya. Dua konsep lainnya, karakteristik pekerjaan dan lingkungan tempat tinggal pelaku memiliki nilai koefisien $\alpha \geq 0.60$ sebagai nilai ambang bawah untuk menyatakan kedua konsep reliabel serta nilai-nilai korelasi $\geq 0,30$.

\section{B. Profil Responden}

Secara deskriptif, komposisi gender dari responden hampir berimbang, 53 persen (64 orang) laki-laki dan 47 persen (56 orang) perempuan. Kelompok umur dari responden dominan ada pada kelompok 30-39 tahun dengan persentase 45 persen (Gambar 1).

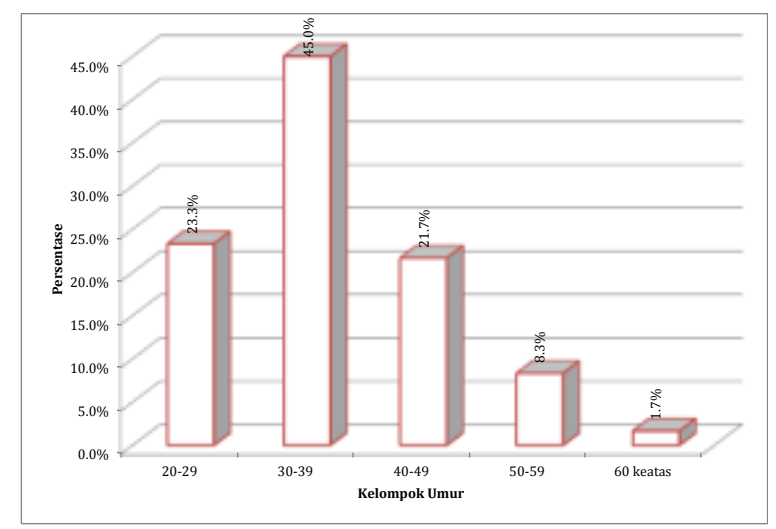

Gambar 1. Profil Umur Responden

Pada karakteristik pekerjaan dan pendidikan tertinggi responden, secara deskriptif pekerja swasta dan wiraswasta mendominasi jenis pekerjaan responden, meski terdapat juga responden bekerja sebagai aparatur sipil negara (ASN) dan polisi. Sebagian besar responden berpendidikan setidak-tidaknya SMA/sederajat. 


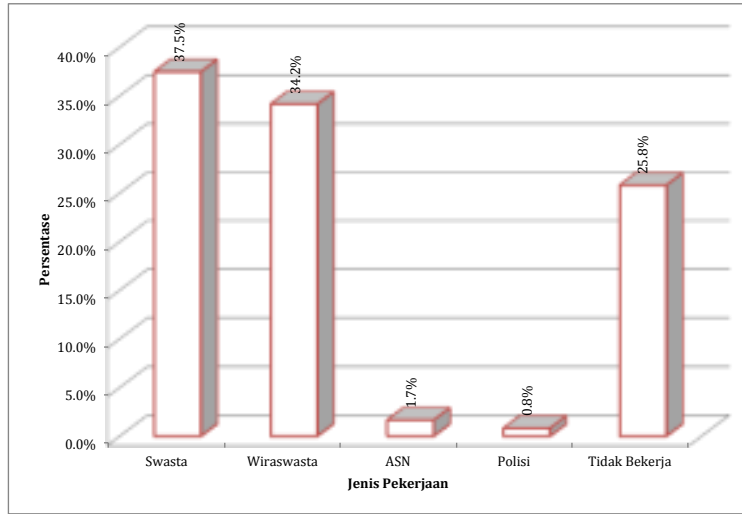

Gambar 2. Profil Jenis Pekerjaan

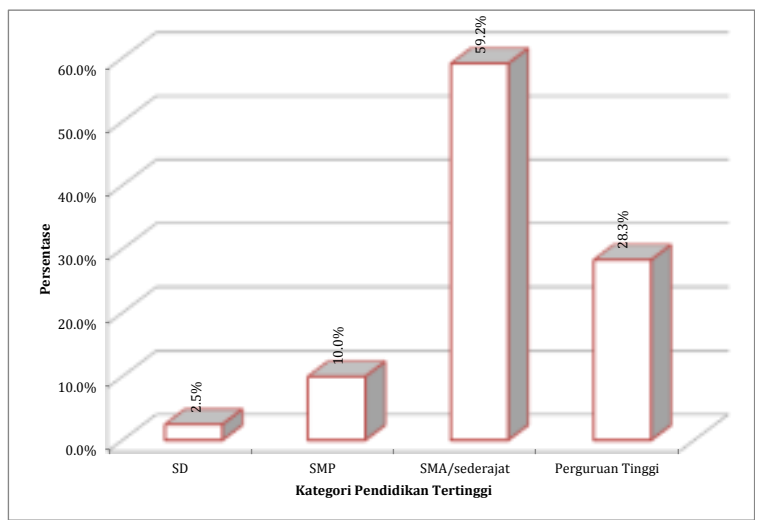

Gambar 3. Profil Pendidikan Tertinggi

\section{Analisis Faktor}

Merujuk Hair et al. [4], terdapat dua tipe Analisis Faktor (AF) yang bisa dipilih peneliti, yaitu Explanatory dan Confirmatory Factor Analysis (EFA dan CFA). Bila CFA digunakan untuk tujuan mengkonfirmasi konsep, maka EFA justru dimanfaatkan untuk membangun konsep dari sejumlah variabel yang diteliti. Pada penelitian ini, sesuai dengan tujuan, EFA diaplikasikan untuk mengetahui faktor-faktor yang memicu tindak KDRT di Kota Denpasar.

Memperhatikan dari 21 item pernyataan kuesioner yang tersisa setelah $\mathrm{X}_{17}$ dieliminasi, reduksi dari 21 item menjadi faktor-faktor yang diwakilinya dilakukan dengan menggunakan EFA melalui tahapan-tahapan seperti uraian berikut $[4,6]$ :

\section{a. Pemeriksaan Kelayakan Matriks Data}

Matriks data $\boldsymbol{X}$ berukuran $p \times n$ diperiksa kelayakannya untuk dilakukan Analisis Faktor (AF) melalui nilai statistik Kaiser-Meyer-Olkin (KMO) dan statistik uji Bartlett. Statistik KMO menunjukkan apakah jumlah data memadai untuk dilakukan AF. Menurut Hair et al (2010), AF layak digunakan bila nilai KMO > 0.5, dan uji Bartlett digunakan untuk mengetahui apakah terjadi korelasi signifikan antaritem pada matriks data. Jika nilai $\chi^{2}$ pada uji ini nyata pada taraf signifikansi yang dipilih, maka AF layak digunakan untuk mereduksi jumlah variabel.

Hasil analisis dengan SPSS memperlihatkan nilai $\mathrm{KMO}=0.614$ dan nilai aproksimasi $\chi^{2}=$ 596.85 signifikan pada taraf uji 1 persen. Memperhatikan kedua nilai ini, bisa disimpulkan AF sah digunakan untuk mereduksi variabel pada matriks data.

\section{b. Pemeriksaan Nilai MSA}

Saat AF diaplikasikan, sebelum faktorfaktor yang diekstraksi diinterpretasikan, nilai masure of sampling adequacy (MSA) yang menunjukkan kelayakan suatu variabel disertakan dalam AF perlu diperiksa. Hasil analisis memperlihatkan 3 item yaitu $X_{11}, X_{32}$, dan $\mathrm{X}_{52}$ memiliki nilai MSA $\leq 0.50$ yang mengindikasikan ketiga item tidak layak disertakan dalam AF (Hair et al, 2010). Memperhatikan hal ini, tahapan AF menggunakan 17 item tersisa diulang.

AF kedua yang dilakukan memberikan nilai $\mathrm{KMO}=0.674$ dan statistik $\chi^{2}=459.37$ signifikan pada taraf uji 1 persen. Seluruh nilai MSA pada item tersisa juga memiliki nilai melebihi nilai ambang 0.50. Mengacu kepada ketiga ukuran kelayakan ini, maka pembentukan faktor dan interpretasinya bisa dilakukan.

\section{c. Pemeriksaan Komunalitas}

Dalam AF, factor loading ( $h$ ) menunjukkan nilai korelasi antara variabel asli dengan faktor yang dibentuk. Nilai $h^{2}$ menunjukkan besar keragaman $\mathrm{X}_{\mathrm{p}}$ yang terjelaskan oleh $\mathrm{F}_{\mathrm{j}}$. Untuk $m$ faktor yang diekstraksi, $\sum_{i=1}^{m} h_{i}^{2}$ merupakan nilai komunalitas dari variabel asal $\mathrm{X}_{\mathrm{p}}$.

Komunalitas perlu diperhatikan untuk mengetahui apakah $X_{\mathrm{p}}$ layak disertakan dalam AF. Sebagai rule-of-thumb, nilai 0.50 bagi $h^{2}$ merupakan ambang untuk menyertakan $X_{p}$ dalam AF. Pemeriksaan pada hasil AF memperlihatkan seluruh variabel asal memiliki komunalitas $\geq$ 
0.50 dan $\mathrm{X}_{21}$ (pendapatan pelaku yang tidak tetap) serta $\mathrm{X}_{54}$ (penegakan hukum bagi pelaku tindak KDRT yang masih lemah) merupakan dua variabel dengan komunalitas tertinggi dan terendah dari 21 variabel asal, masing-masing dengan nilai $h^{2}$ sebesar 0.74 dan 0.51 . Jadi, seluruh variabel asal layak diekstraksi.

\section{d. Ekstraksi dan Rotasi Faktor}

Untuk menentukan jumlah faktor yang diekstraksi, peneliti menggunakan kriteria nilai eigen. Faktor dengan nilai eigen $>1$ dipilih. Untuk mengkonfirmasi jumlah faktor yang diekstraksi, juga diperiksa scree plot yang menggambarkan hubungan antara jumlah faktor dengan nilai eigennya. Brown et al. (2012) menyarankan jumlah faktor yang layak diekstraksi adalah saat plot mulai menunjukkan pola 'landai', seperti terlihat pada Gambar 4.

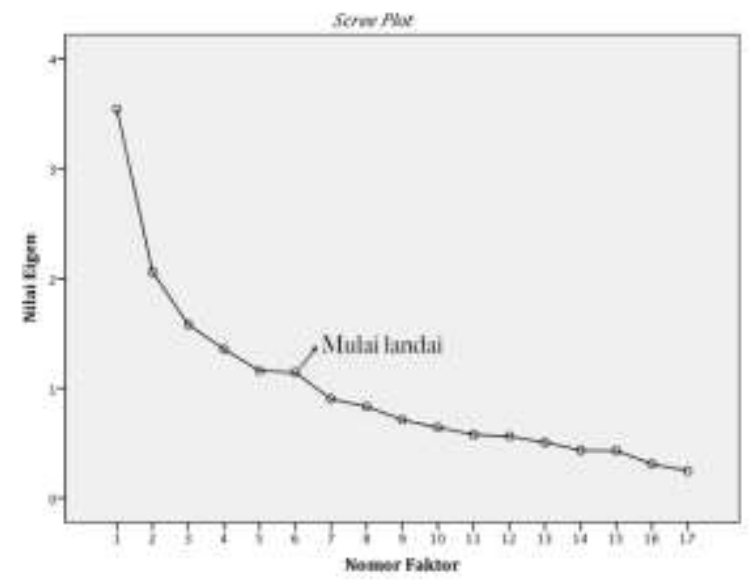

Gambar 4. Scree Plot dari Analisis Faktor

Merujuk kepada Gambar 4 dan menetapkan jumlah faktor yang diekstraksi berdasarkan kriteria nilai eigen $>1$, diperoleh 6 faktor dari 17 variabel asal. Untuk memudahkan interpretasi, maka dilakukan transformasi orthogonal pada matriks komponen $\Lambda$ yang anggotanya nilainilai $h$. Menggunakan rotasi Varimax, diperoleh matrik komponen yang dirotasi sebagai disajikan pada Tabel 2.

Pada Tabel 2 sel-sel yang diberikan latar belakang menunjukkan nilai-nilai $h$ variabel yang terekstraksi menjadi faktor tertentu. Pada $\mathrm{F}_{5}$ terlihat $h_{35}$ memiliki koefisien negatif. Mencermati salah satu sifat faktor yang diekstraksi harus unidimensional (Bollen, 2002)
- variabel penyusunnya searah ditunjukkan oleh tanda (sign) $h$ sama - maka $\mathrm{X}_{35}$ dikeluarkan dan AF diulang.

Tabel 2. Matrik Komponen Setelah Dirotasi

\begin{tabular}{|l|r|r|r|r|r|r|}
\hline \multirow{2}{*}{ Var. } & \multicolumn{7}{|c|}{ Faktor } \\
\cline { 2 - 7 } & $\mathrm{F}_{1}$ & $\mathrm{~F}_{2}$ & $\mathrm{~F}_{3}$ & $\mathrm{~F}_{4}$ & $\mathrm{~F}_{5}$ & $\mathrm{~F}_{6}$ \\
\hline $\mathrm{X}_{41}$ & 0.80 & 0.04 & 0.02 & 0.05 & -0.07 & 0.09 \\
\hline $\mathrm{X}_{42}$ & 0.77 & 0.08 & 0.08 & 0.24 & 0.03 & 0.14 \\
\hline $\mathrm{X}_{54}$ & 0.57 & -0.06 & 0.08 & -0.16 & 0.38 & -0.03 \\
\hline $\mathrm{X}_{51}$ & 0.06 & 0.72 & 0.10 & 0.22 & -0.09 & 0.10 \\
\hline $\mathrm{X}_{43}$ & 0.29 & 0.71 & 0.11 & 0.01 & -0.09 & 0.35 \\
\hline $\mathrm{X}_{14}$ & -0.19 & 0.67 & 0.01 & 0.04 & 0.24 & -0.28 \\
\hline $\mathrm{X}_{16}$ & -0.29 & 0.45 & 0.42 & 0.01 & 0.41 & 0.01 \\
\hline $\mathrm{X}_{13}$ & -0.03 & 0.17 & 0.82 & 0.07 & 0.05 & 0.00 \\
\hline $\mathrm{X}_{15}$ & 0.14 & -0.11 & 0.74 & 0.20 & -0.08 & 0.17 \\
\hline $\mathrm{X}_{12}$ & 0.28 & 0.39 & 0.54 & -0.08 & -0.05 & -0.20 \\
\hline $\mathrm{X}_{31}$ & 0.12 & 0.00 & 0.03 & 0.78 & 0.20 & -0.07 \\
\hline $\mathrm{X}_{34}$ & -0.01 & 0.25 & 0.20 & 0.73 & -0.11 & 0.12 \\
\hline $\mathrm{X}_{53}$ & 0.21 & 0.11 & -0.15 & 0.22 & 0.64 & 0.19 \\
\hline $\mathrm{X}_{35}$ & 0.27 & 0.37 & 0.02 & 0.32 & -0.56 & 0.03 \\
\hline $\mathrm{X}_{33}$ & 0.40 & 0.06 & 0.27 & 0.30 & 0.49 & 0.09 \\
\hline $\mathrm{X}_{21}$ & -0.08 & 0.08 & -0.13 & 0.00 & 0.36 & 0.76 \\
\hline $\mathrm{X}_{22}$ & 0.25 & 0.01 & 0.18 & 0.05 & -0.07 & 0.73 \\
\hline
\end{tabular}

Sumber: Data primer, dianalisis (2016)

Hasil analisis ulang pada 16 variabel setelah $\mathrm{X}_{35}$ dikeluarkan memberikan nilai $\mathrm{KMO}=0.682$ $>0.50$, nilai aproksimasi $\chi^{2}=415.35$ (signifikan pada taraf uji 1 persen), dan jumlah faktor yang diekstraksi (dengan nilai eigen > 1) sebanyak enam faktor. Hasil akhir AF dari matriks komponen setelah dirotasi varimax ditunjukkan pada Tabel 3.

Pada Tabel 3 terlihat seluruh $h$ dari $\mathrm{X}_{\mathrm{p}}$ yang terekstraksi menjadi $F_{j}$ memiliki tanda yang sama yang mengindikasikan unidimensionalitas faktor telah terwakili. Memperhatikan hal ini maka interpretasi faktor-faktor yang terekstraksi dapat dilakukan. 
Tabel 3. Matrik Komponen Akhir

\begin{tabular}{|l|r|r|r|r|r|r|}
\hline \multirow{2}{*}{ Var. } & \multicolumn{7}{|c|}{ Faktor } \\
\cline { 2 - 7 } & $\mathrm{F}_{1}$ & $\mathrm{~F}_{2}$ & $\mathrm{~F}_{3}$ & $\mathrm{~F}_{4}$ & $\mathrm{~F}_{5}$ & $\mathrm{~F}_{6}$ \\
\hline $\mathrm{X}_{51}$ & 0.73 & 0.13 & 0.11 & -0.09 & 0.10 & 0.23 \\
\hline $\mathrm{X}_{43}$ & 0.71 & 0.35 & 0.13 & -0.02 & 0.34 & 0.01 \\
\hline $\mathrm{X}_{14}$ & 0.69 & -0.26 & -0.02 & 0.15 & -0.25 & 0.06 \\
\hline $\mathrm{X}_{16}$ & 0.45 & -0.45 & 0.38 & 0.30 & 0.06 & 0.04 \\
\hline $\mathrm{X}_{41}$ & 0.07 & 0.84 & 0.05 & 0.13 & 0.04 & 0.04 \\
\hline $\mathrm{X}_{42}$ & 0.07 & 0.74 & 0.11 & 0.28 & 0.10 & 0.21 \\
\hline $\mathrm{X}_{13}$ & 0.18 & -0.08 & 0.80 & 0.04 & 0.00 & 0.09 \\
\hline $\mathrm{X}_{15}$ & -0.12 & 0.13 & 0.75 & -0.01 & 0.16 & 0.20 \\
\hline $\mathrm{X}_{12}$ & 0.38 & 0.21 & 0.57 & 0.10 & -0.22 & -0.10 \\
\hline $\mathrm{X}_{53}$ & 0.10 & -0.01 & -0.16 & 0.68 & 0.22 & 0.20 \\
\hline $\mathrm{X}_{54}$ & -0.11 & 0.31 & 0.12 & 0.66 & -0.03 & -0.24 \\
\hline $\mathrm{X}_{33}$ & 0.06 & 0.21 & 0.26 & 0.60 & 0.11 & 0.29 \\
\hline $\mathrm{X}_{21}$ & 0.08 & -0.14 & -0.15 & 0.25 & 0.79 & 0.02 \\
\hline $\mathrm{X}_{22}$ & -0.02 & 0.28 & 0.21 & 0.02 & 0.71 & 0.02 \\
\hline $\mathrm{X}_{31}$ & 0.01 & 0.10 & 0.02 & 0.21 & -0.07 & 0.78 \\
\hline $\mathrm{X}_{34}$ & 0.24 & 0.05 & 0.22 & -0.06 & 0.11 & 0.72 \\
\hline
\end{tabular}

Sumber: Data primer, dianalisis (2016)

Tabel 4. Hasil Ekstraksi Faktor

\begin{tabular}{|c|c|c|c|c|c|}
\hline \multicolumn{2}{|c|}{ Faktor Diekstraksi } & $\begin{array}{r}\text { Nilai } \\
\text { Eigen }\end{array}$ & $\begin{array}{r}\text { Ragam } \\
\text { Asli }\end{array}$ & $\begin{array}{r}\text { Ragam } \\
\text { Rotasi }\end{array}$ & $\begin{array}{l}\text { Var. } \\
\text { Asal }\end{array}$ \\
\hline \multirow{4}{*}{$\mathrm{F}_{1}$} & \multirow{4}{*}{$\begin{array}{l}\text { Faktor } \\
\text { Relasi Sosial }\end{array}$} & \multirow{4}{*}{3.422} & \multirow{4}{*}{21.39} & \multirow{4}{*}{12.43} & $X_{51}:$ \\
\hline & & & & & $X_{43}$ \\
\hline & & & & & $\mathrm{X}_{14}$ \\
\hline & & & & & $\mathrm{X}_{16}$ \\
\hline \multirow{2}{*}{$\mathrm{F}_{2}$} & \multirow{2}{*}{$\begin{array}{l}\text { Faktor } \\
\text { Pekerjaan }\end{array}$} & \multirow{2}{*}{2.052} & \multirow{2}{*}{12.83} & \multirow{2}{*}{12.29} & $X_{41}$ \\
\hline & & & & & $X_{42}$ \\
\hline \multirow{3}{*}{$\mathrm{F}_{3}$} & \multirow{3}{*}{$\begin{array}{l}\text { Faktor } \\
\text { Pengalaman } \\
\text { Masa Lalu }\end{array}$} & \multirow{3}{*}{1.466} & \multirow{3}{*}{9.16} & \multirow{3}{*}{12.07} & $X_{13}$ \\
\hline & & & & & $X_{15}$ \\
\hline & & & & & $\mathrm{X}_{12}$ \\
\hline \multirow{3}{*}{$\mathrm{F}_{4}$} & \multirow{3}{*}{$\begin{array}{l}\text { Faktor } \\
\text { Pendukung } \\
\text { KDRT }\end{array}$} & \multirow{3}{*}{1.203} & \multirow{3}{*}{7.52} & \multirow{3}{*}{10.02} & $\mathrm{X}_{53}$ \\
\hline & & & & & $\mathrm{X}_{54}$ \\
\hline & & & & & $\mathrm{X}_{33}$ \\
\hline \multirow{2}{*}{$\mathrm{F}_{5}$} & \multirow{2}{*}{$\begin{array}{l}\text { Faktor } \\
\text { Ekonomi RT }\end{array}$} & \multirow{2}{*}{1.156} & \multirow{2}{*}{7.23} & \multirow{2}{*}{9.22} & $X_{21}$ \\
\hline & & & & & $\mathrm{X}_{22}$ \\
\hline \multirow{2}{*}{$\mathrm{F}_{6}$} & \multirow{2}{*}{$\begin{array}{l}\text { Faktor } \\
\text { Kebersamaan }\end{array}$} & \multirow{2}{*}{1.131} & \multirow{2}{*}{7.07} & \multirow{2}{*}{9.16} & $X_{31}$ \\
\hline & & & & & $\mathrm{X}_{34}$ \\
\hline & Total & 10.43 & 65.19 & 65.19 & \\
\hline
\end{tabular}

Sumber: Data primer, dianalisis (2016)

\section{e. Interpretasi Faktor}

Seperti diperlihatkan pada Tabel 3, perotasian tidak mengubah besarnya total ragam dari matriks data yang dijelaskan oleh 6 faktor yang diekstraksi, sebesar 65.19 persen. Rotasi hanya mendistribusikan keragaman data agar lebih mudah diinterpretasikan.

Faktor relasi sosial, yang diekstraksi dari empat variabel asal, yang sesuai dengan pernyataan Rahayuningsih (2008) bahwa tidak terjalinnya hubungan yang baik dengan rekan kerja dapat berdampak pada perilaku pelaku dalam kehidupan berumah tangga. Faktor ini mampu menjelaskan kera-gaman matriks data, sebelum dirotasi, sebesar 21.39 persen. Bila nilai $h$ dari setiap variabel asal yang diekstraksi menjadi faktor ini dicermati (lihat Tabel 2), variabel $\mathrm{X}_{51}$ (hubungan dengan tetangga yang kurang baik) memiliki loading terbesar, disusul oleh $\mathrm{X}_{43}$ (hubungan dengan rekan kerja kurang baik). Memperhatikan hal ini, maka bisa disimpulkan kualitas relasi sosial dari pelaku tindak KDRT merupakan faktor dominan pemicu terjadinya KDRT di Kota Denpasar.

Faktor kedua yang diekstraksi dari dua variabel asal menjelaskan keragaman data sebesar 12.83 persen. Variabel $\mathrm{X}_{41}$ dengan loading 0.84 mengungguli $\mathrm{X}_{42}$ sebesar yang memiliki nilai 0.74 . Tingginya tingkat kesulitan kerja $\left(\mathrm{X}_{41}\right)$ serta risiko kerja $\left(\mathrm{X}_{42}\right)$ yang diekstraksi menjadi faktor pekerjaan menjadi pemicu kedua tindak KDRT. Temuan ini sejalan dengan pendapat Ihromi (1999) dalam Manumpahi et al (2016) yang menyatakan permasalahan di bidang kerja yang dihadapi seorang suami, dibarengi dengan tuntutan istri agar suami menafkahi keluarganya, bisa memicu emosi suami untuk melakukan tindak KDRT.

Faktor ketiga, pengalaman masa lalu pelaku, diekstraksi dari 3 variabel asal, dengan $\mathrm{X}_{13}$ (memiliki kecendrungan paranoid) dan $\mathrm{X}_{15}$ (memiliki pengalaman buruk di masa lalu) sebagai variabel-variabel dengan $h$ terbesar, merupakan faktor ketiga yang memicu tindak KDRT di Kota Denpasar.

Tiga faktor lainnya, pendukung KDRT, ekonomi rumah tangga, dan kebersamaan 
merupakan tiga faktor pemicu yang lain dengan keragaman data yang dijelaskan masing-masing sebesar 7.52, 7.23, dan 7.07 persen. Bila dibandingkan dengan ketiga faktor sebelumnya, ternyata situasi ekonomi rumah tanggga pelaku bukan menjadi pemicu dominan tindak KDRT di Kota Denpasar, seperti diungkapkan oleh Prantiasih et al. (2015), kekerasan fisik sebagai salah satu bentuk KDRT disebabkan oleh pekerjaan pelaku (suami) yang tidak bekerja atau memiliki pekerjaan yang bersifat tidak tetap dengan penghasilan tidak menentu.

\section{SIMPULAN DAN SARAN}

\section{A. Simpulan Penelitian}

Penelitian tentang faktor-faktor pemicu tindak KDRT di Kota Denpasar menyimpulkan beberapa hal:

1. Terdapat 6 faktor yang teridentifikasi sebagai pemicu tindak KDRT di Kota Denpasar. Keenam faktor hasil ekstraksi dari 16 variabel asal adalah: (a) kualitas relasi sosial dari pelaku, (b) karakteristik pekerjaan pelaku, (c) pengalaman masa lalu, (d) pendukung KDRT, (e) perekonomian rumah tangga, dan (f) waktu bersama keluarga;

2. Kualitas relasi sosial merupakan faktor dominan yang memicu tindak KDRT di Kota Denpasar. Kualitas relasi sosial meliputi kualitas hubungan bertetangga, dan kualitas hubungan rekan kerja.

\section{B. Saran}

Untuk memverifikasi hasil penelitian ini, disarankan untuk melengkapi data dengan analisis kualitatif seperti focus group discussion dan wawancara mendalam.

\section{DAFTAR PUSTAKA}

Arbaiyah Prantiasih, M. Yuhdi, and Siti Awaliyah, "Model Perlindungan Hak Perempuan Korban Tindak Kekerasan dalam Rumah Tangga," Jurnal Pendidikan Pancasila dan Kewarganegaraan, vol. 28, no. 1, pp. 15-19, Februari 2015.

Bruce L Brown, Suzanne B Hendrix, Dawson W Hedges, and Timothy B Smith, Multivariate Analysis for the Biobehavioral and Social Sciences. Canada: John Wiley \& Sons, 2012.

Edwin Manumpahi, Shirley Y.V.I. Goni, and Hendrik W. Pongoh, "Kajian Kekerasan dalam Rumah Tangga Terhadap Psikologi Anak di Desa Soakonora Kecamatan Jailolo Kabupaten Halmahera Barat," e-journal "Acta Diurna", vol. 5, no. 1, pp. 1-15, 2016.

J Hair, RE Anderson, RL Tatham, and WC Black, Multivariate Data Analysis With Reading, Fourth Edition. New Jersey: Prentice Hall International Edition, 2010.

Jr. G.A Churchill, "A Paradigm for Developing Better Measures of Marketing Constructs.," Journal of Marketing Research, pp. 64-73, 1979.

Lely Setyowati Kurniawan, Refleksi Diri Para Korban dan Pelaku Kekerasan dalam Rumah Tangga. Jakarta: CV. Andi Offset, 2015.

Kenneth A. Bollen, "Latent Variables in Psychology and the Social Sciences," Annual Review of Psychological, vol. 53, pp. 605634, 2002. 